\title{
Doença na família: uma discussão sobre o cuidado psicológico do familiar cuidador*
}

\author{
Cristiane Alves Dias ${ }^{l}$ \\ Denise Nuernberg ${ }^{2}$ \\ Universidade do Extremo Sul Catarinense
}

A doença gera grandes transformações no ambiente familiar, pois é preciso zelar, dar atenção e cuidar do doente. $\mathrm{O}$ presente artigo discute as principais necessidades da pessoa que vai cuidar do doente, pois possui a função de cuidar do paciente, promovendo seu bem estar físico, psicológico e social, mas este acompanhante também precisa de suporte psicológico e estrutura física adequada para o cuidado com o doente, sendo esta uma tarefa difícil, principalmente no aspecto psicológico. Neste sentido, este artigo objetiva-se em compreender a importância e a necessidade de acolhimento ao acompanhante - geralmente um familiar- do paciente hospitalizado. Trata-se de uma pesquisa de campo de natureza qualitativa que utilizou como ferramenta de pesquisa entrevista com seis acompanhantes de pacientes do Setor de Oncologia do Hospital São José da cidade de Criciúma/SC. No qual se observou que estes acompanhantes necessitam de maior acolhimento por parte do hospital e profissionais da saúde.
The illness generates big transformations in the family environment; therefore, we need to ensure and take care of the ill. The present article discusses the principles for the person who is going to take care of the ill; therefore, the function of this caregiver promotes their caretaker's wellbeing, but this caregiver also needs a psychological as well as a physical support system in order for better care, which can be a difficult task, principally in the psychological aspect. In this sense this article's objective is to understand the importance, needs, and observations of the caregiver, generally a family member of the hospitalized. It is field research in the qualitative nature that family members are generally used as a search tool, in this case through interviews, six caregivers of the patients from the Section of Oncology from San Jose Hospital in the city of Criciúma/SC, Brought up the realization that caregivers required greater attention by the hospital and the professionals in health.

\footnotetext{
"An illness in the family: a discussion about the psychological caretaking of a family caregiver

${ }^{1}$ Curso de Graduação em Psicologia da Universidade do Extremo Sul Catarinense. Endereço para correspondências: Rua Lourenço Zanette, 335, Bloco 10, Apto. 302, Criciúma, SC, 88809-470 (crisdias43@hotmail.com).

${ }^{2}$ Coordenadora do Curso de Graduação em Psicologia da Universidade do Extremo Sul Catarinense. Endereço para correspondências: Rua Coronel Pedro Benedet, 363, Edifício San Vicente, Sala 809, Centro, Criciúma, SC, 88801-250 (den@unesc.net e psicologia@unesc.net).
} 
Palavras-chave: Doença - Família Cuidador - Hospital
Keywords: Disease - Family - Caretaker - Hospital

\section{Introdução}

$\mathrm{O}$ ser humano nasce, cresce e morre. Ao decorrer desse desenvolvimento pode adoecer e não conseguir completar todas as fases. Quando a doença afeta o sujeito, pode afetar todo o grupo familiar, tornando-se então necessária a assistência psicológica, estendida a todos os membros da família. Nesse sentido, destaca-se a relevância deste artigo, na tentativa de buscar subsídios para que os futuros psicólogos possam dar suporte à família do doente, e principalmente ao cuidador, haja vista que quando ocorre uma doença na família, todos sofrem e dependendo do grau de afetividade entre eles, muitos problemas emocionais podem surgir.

Observa-se que muito diferente da prática hospitalar, o paciente não deve ser tratado apenas com medicamentos, existindo a necessidade de atendimento psicológico, tanto aos pacientes, quanto aos familiares. Para estes, a psicologia deverá auxiliar informando a situação em que se encontra o paciente hospitalizado, esclarecendo aspectos relacionados à doença e que podem ser desconhecidos, o que pode aumentar a preocupação. De modo que quando há compreensão e aceitação da doença, se tornam mais fáceis o tratamento e a recuperação do paciente (ROMANO, 1999).

Constata-se que no caso de doença o paciente sofre a dor física e a psicológica, a família sente a dor psíquica, o que poderá levá-la ao processo de adoecer biologicamente. Assim, o psicólogo pode intervir junto à família, transmitindo segurança, conversando sobre os medos, além de estabelecer vínculo com a equipe hospitalar; pois os outros profissionais da área da saúde, como médicos e enfermeiros, exercem suas funções priorizando a parte física do sujeito; no entanto, a parte psicológica também merece a devida atenção. Por conseguinte, a atuação multiprofissional colaboraria nesse sentido, pois tornaria as informações mais precisas, evitando dúvidas com relação à doença (ROMANO, 1999).

Nos casos em que existe a necessidade de internação, a situação se agrava, pois além do desgaste psicológico, começa a existir o desgaste físico dos acompanhantes, que não encontram um espaço adequado para descansar enquanto permanecem no ambiente hospitalar.

Grupos de apoio podem ajudar nesse momento, pois se os familiares compartilharem sentimentos com pessoas que se encontram em situação semelhante ou piores que as suas, poderão perceber que não estão sós. Existe então, a necessidade de um ambiente dentro do hospital, no qual os 


\section{Doença na família: uma discussão sobre o familiar cuidador}

familiares ou acompanhantes sintam-se à vontade para compartilhar experiências e descansar enquanto estiverem no papel de cuidadores, pois é um momento em que poderão criar vínculos, auxiliando uns aos outros, facilitando o processo que estão enfrentando. É diante destes aspectos que se justifica o presente artigo.

\section{Quando a doença surge na família}

Conforme Prado e Damiani (1986), a palavra família, no sentido popular, significa pessoas com laços parentais que vivem numa mesma casa como pais, mães e filhos ou ainda, pessoas que possuem laços sanguíneos, ou seja, família nuclear. No entanto, a família não necessariamente precisa seguir esses padrões para que seja considerada família. Pessoas que convivem diariamente, mas que não possuem laços sanguíneos, também podem ser consideradas como família (CARTER \& MCGOLDRICK, 2001).

Minuchin (1990) demonstra que a família opera como um sistema aberto e em transformação, que se adapta às exigências do seu ciclo vital. Esse sistema atua de forma natural, agindo de acordo com cada cultura familiar. Para Carter e Mcgoldrick (2001), a família vai além da soma das partes; a vida de cada sujeito acontece dentro do ciclo familiar.

De acordo com Relvas (2000; p. 10), "a família é entendida como um sistema, um todo, uma globalidade". Osório (1996) ressalta que a família possui seu ciclo vital, ou seja, ela nasce, cresce, amadurece e se reproduz em outras famílias, que encerram seu ciclo vital quando chegam à morte. Entre algumas funções sociais da família, pode-se destacar o papel de cumprir as funções na promoção do desenvolvimento biopsicossocial do indivíduo.

Considerando então que a família é composta por pai, mãe e filhos, ponderando ainda o papel que cada um tem dentro do sistema familiar, pode-se entender que dependendo de qual membro do sistema adoece, a família reagirá diferentemente para cada caso.

Para Carter e Mcgoldrick (2001), quando um familiar adoece, todo o sistema é afetado. No geral, a doença aproxima os membros de uma família, acionando o processo de socialização com a enfermidade. "Os sintomas, a perda de função, as exigências de mudança, relacionadas à doença, nos papéis práticos e afetivos, e o medo da perda através da morte, tudo isso serve para que a família crie um novo foco interno" (CARTER \& MCGOLDRICK 2001, p. 386). No entanto, os autores supra citados afirmam que as doenças graves provocam rupturas na família, podendo-se compreender pelo fato de que é nessa fase do ciclo de vida da família que os indivíduos têm maiores responsabilidades (CARTER \& MCGOLDRICK, 2001). 
Conforme O'Connor (1983; apud ROMANO, 1999) se o equilíbrio e organização da família são alterados frente a um evento qualquer, haverá a necessidade de adaptação. No entanto, essas adaptações dependerão dos recursos que a família dispõe para lidar com a crise e da importância que esse acontecimento tem para os membros. Sá (2002) ressalta que a família que recebe o diagnóstico da doença, avalia como algo ameaçador e grave, pois existem planos e uma cultura de vida sentidos como algo interrompido, veemse como se estivessem diante do fim.

A criança que vivencia na família um momento de doença e hospitalização, sente-se deixada de lado, sendo, por exemplo, o familiar hospitalizado um irmão, poderá sentir-se abandonada pelos pais que depositam toda atenção no filho doente. A partir de então, esses filhos sentem-se culpados pela doença do outro e ainda sentem medo de adoecer também (SÁ, 2002).

Quando se fala em adolescência constata-se que o adoecimento de um dos pais interfere na conquista de independência do adolescente, podendo colocá-lo como um substituto paterno ou materno em relação aos irmãos. Quando a doença é vivenciada na família por um cônjuge, aumentam as responsabilidades financeiras, domésticas e emocionais, pois agora é necessário cuidar do outro e ainda assumir suas responsabilidades (CARTER \& MCGOLDRICK, 2001).

Quando o adolescente torna-se enfermo, poderá rebelar-se contra a família, principalmente em relação aos pais. Já nos irmãos do adolescente doente, poderão despertar sentimentos como ciúmes pela dedicação dos pais em relação ao filho doente, e poderão sentir-se culpados por isso. $\mathrm{O}$ sentimento de impotência frente ao sofrimento de um familiar doente, principalmente em casos em que o membro da família está hospitalizado, gera um estresse emocional familiar de alta intensidade. As manifestações vivenciadas pela família no processo de adoecer são variadas, mas o processo da família permanece essencialmente o mesmo (CARTER \& MCGOLDRICK, 2001).

Segundo Kübler-Ross (2000, p. 163), "no período da doença os familiares desempenham papel preponderante, e suas reações muito contribuem para a própria reação do paciente". No entanto, ressalta a necessidade que os membros da família têm em dosar suas energias para que não esgotem suas forças e as tenham quando for necessário.

Ainda de acordo com Carter e Mcgoldrick (2001), nos casos de doenças graves, como o câncer, os membros da família sofrem um estresse de permanente incerteza, pois essas doenças são muito instáveis quanto ao seu curso. As emoções tornam-se muito inconstantes, pois em cada melhora do paciente vem a esperança de vida e em cada recaída, o medo da morte. Essa oscilação e a constante incerteza podem esgotar a família emocionalmente. 


\section{Doença na família: uma discussão sobre o familiar cuidador}

De acordo com a pesquisa realizada por Celich e Batistella (2007) com familiares cuidadores de portadores da Doença de Alzheimer na cidade de Erechim/RS, tomam-se como exemplo, as narrativas dos entrevistados que se referem ao sofrimento que passam diariamente esses cuidadores. Nos relatos, os entrevistados falam que enfrentam diversas dificuldades como o cansaço e referem-se ainda à necessidade de serem cuidados também, além de falta de tempo para dedicação à família. Apresentam ainda sintomas físicos como dificuldade para dormir, depressões e estresse.

Para Kübler-Ross (2000), a falta de comunicação pode afetar o sistema familiar durante a doença. É natural que os familiares ocultem dos pacientes os sentimentos, tentando passar para ele força. No entanto, a autora argumenta que o paciente também poderá ajudar os familiares fazendo com que encarem sua morte, participando dos pensamentos e sentimentos dos membros da família. Ressalta ainda que se o paciente for capaz de enfrentar a morte com tranquilidade, os familiares a suportarão e terão força ao se lembrarem da tranqüilidade do paciente.

Conforme Waldow (2007), a hospitalização é um evento que gera temor nas pessoas, pois a doença é vista como ameaçadora e o estar doente é algo que se caracteriza por uma ruptura na relação do indivíduo com o mundo, visto que as capacidades que eram possíveis agora já não são mais.

De uma forma geral, Romano (1999) ressalta que o adoecimento e hospitalização de um dos membros da família geram estresse no grupo familiar, pois é entendido como algo ameaçador, causando um desequilíbrio no grupo, e se o equilíbrio da família não é restaurado, gera então uma crise que pode ser evidenciada pelas respostas físicas ou emocionais dos membros. Alguns sinais em resposta a crise devem ser observados e podem ser exemplificados como: dificuldade para dormir e com baixa qualidade de sono, alteração na alimentação, uso de drogas lícitas como cigarros, álcool e calmantes. Alguns sentimentos tais como culpa, sentimento de abandono, menos valia, medo e raiva, provenientes da ansiedade, também são manifestados no grupo familiar.

Existe ainda o medo da morte, que segundo Feifel (1959; apud KOVÁCS, 2008), esse é diferente para cada indivíduo conforme a maturidade psicológica de cada um, a capacidade de enfrentamento, a religiosidade e até mesmo a idade do sujeito. O medo da morte inicia-se na infância, não é algo inato, a criança entra em contato com a morte gradativamente por meio das experiências de seus pais. Então, tal temor dependerá da natureza e é inerente ao processo do crescimento (KOVÁCS, 2008). Nos casos de familiares de pacientes hospitalizados, esse medo poderá surgir quando o paciente tem uma melhora em que surge uma esperança de cura que é seguida por uma recaída. 


\section{O cuidador}

O verbo cuidar, de acordo com Grandi (1998), significa assistir, ter atenção e cuidados com alguém ou consigo mesmo, ou ainda, significa dar amparo, assistência, proteção e representação, uma vez que o cuidador torna-se mediador e o executor das atividades entre o paciente e a realidade que o cerca. $\mathrm{O}$ cuidar significa zelar, dar atenção, desvelo. O cuidado somente surge quando a existência de alguém tem importância para o cuidador (BOFF, 2008). "Cuidar é estimular e incentivar a maior autonomia e independência possível do paciente, permitindo a superação de obstáculos" (GRANDI, 1998; p. 72). Para Waldow (2007), o ato de cuidar inclui afeto e consideração, significa agir no sentido de promover o bem-estar do outro. Osório (2003) afirma que os cuidadores têm a função de cuidar dos pacientes promovendo seu bem-estar físico, psicológico e social.

$\mathrm{O}$ ato de cuidar é algo que já existe há muito tempo. De acordo com Foucault (1981; apud LAHAM, 2004), os hospitais não tinham a função de cuidar dos pacientes, funcionavam apenas como locais onde as pessoas eram depositadas quando fossem morrer. Lá havia pobres e miseráveis que seriam isolados da sociedade a fim de não contagiar o resto da população com doenças. Essa população era cuidada por religiosos ou leigos, e a alta sociedade recebia cuidados domiciliares por médicos.

Albuquerque (2003; apud LAHAM, 2004) pontua que a prática de cuidado domiciliar vem desde o Antigo Testamento, pois ali é citado o cuidado de Jesus com enfermos em suas residências. Já no século XIX, os cuidados domiciliares eram praticados por associações de enfermeiras e no século XX, esses cuidados foram feitos por médicos.

Laham (2004) cita que em 1947, nos EUA, após muitos anos de assistência hospitalar começou-se a praticar o cuidado domiciliar. Em 1951, na França, em virtude das superlotações hospitalares voltou-se então, ao atendimento domiciliar. A partir daí, o cuidado domiciliar voltou a ser praticado, espalhando-se por toda a Europa. Já no Brasil, em 1968, o Hospital do Servidor Público Estadual de São Paulo foi pioneiro dessa prática. Atualmente, o cuidado domiciliar tem a participação de diversos profissionais, oferecendo ao paciente a prevenção de problemas de saúde ou então, a assistência para doenças já instaladas (LAHAM, 2004).

Conforme Waldow (2007; p. 39), "O ser humano, ao longo de seu desenvolvimento, adquire formas e expressões de cuidar que se sofisticam”. Assim sendo, o cuidar inicia-se primeiramente como forma de sobrevivência, em seguida como uma expressão de interesse e carinho. A primeira forma evidencia-se em todas as espécies de seres vivos. Já a segunda é uma particularidade dos seres humanos. Ao longo da história, o modo de expressar cuidado com os que necessitam é mais evidente entre as mulheres pois o parto já era de responsabilidade destas. 


\section{Doença na família: uma discussão sobre o familiar cuidador}

Grandi (1998) acrescenta que o ato de cuidar normalmente é praticado por mulheres, isso porque a mulher ocupa o primeiro lugar entre os cuidadores em potencial, por estarem ligadas historicamente à responsabilidade pelos cuidados dos membros da família.

O cuidador é o responsável direto pelos cuidados do paciente, tanto o físico como o psicológico e o social, tornando-se este, cada vez mais, dependente daquele que o cuida. Assim, o cuidador torna-se a segunda vítima, pois o ato de cuidar gera sobrecarga física e emocional (GRANDI, 1998).

O papel de cuidador não é algo preestabelecido e ninguém está preparado para tal, por isso, quando surge à necessidade de cuidar, cada qual reage de uma maneira, de acordo com suas características particulares. $\mathrm{O}$ cuidador assume um papel que foi imposto pela ocasião, e apesar de existir um desejo muito grande de ajudar o familiar, o cuidador não tem noção da atenção que lhe será exigida. Na ansiedade de ajudar, muitas vezes, o familiar acompanhante ou cuidador esquece que pertence há um grupo familiar e que estes podem colaborar, revezando o acompanhamento e o cuidado ao paciente. Esquece inclusive que também tem uma família, a qual necessita de sua presença (SÁ, 2002).

Conforme Machado (2008), o cuidador vivencia angústias, medo, desesperança e desamparo. Esses sentimentos geram sofrimento e, nos casos em que o cuidador é familiar do paciente, esse sofrimento aumenta, pois existe o envolvimento afetivo e o cuidador sofre com a dor do paciente.

$\mathrm{O}$ ato de acompanhar um paciente hospitalizado é algo difícil e que gera estresse, pois o cuidador familiar sofre dois impactos: primeiramente o do diagnóstico, de saber que alguém que ele ama vai sofrer com a doença, e sofre o impacto de se ver diante a uma situação de acompanhante, de ter que dar força e auxílio total ao paciente familiar, no decorrer da hospitalização (SÁ, 2002).

Para Grandi (1998; p. 72), "a atitude de cuidar não é inata, e sim imposta por circunstâncias". Assim sendo, essa experiência pode ser vivenciada de forma dolorosa pelo cuidador. Normalmente os familiares cumprem os papéis de cuidadores, e são chamados cuidadores informais, pois não há remuneração para tal.

O cuidar é um processo interativo, no qual o cuidador e o paciente envolvem-se, principalmente de forma emocional, pois o ato de cuidar inclui e demonstra amor, atenção, preocupação, promovendo o apoio psicológico no momento em que existe sofrimento do paciente. Entretanto, ao relacionar-se com o paciente, o cuidador também sofre porque ao cuidar vivencia a dor, pois existe o envolvimento emocional inevitável e esse não possibilita a isenção da dor (WALDOW, 2006).

No momento da internação, o familiar normalmente não está preparado para lidar com a situação, no entanto é a pessoa mais próxima do paciente, consequentemente se torna a pessoa mais apta para cuidar. Neste momento o familiar apesar de ser a pessoa mais indicada para estar com paciente, 
é a pessoa que mais sofre, pois se depara com situações que fazem com que seu estado psicológico e emocional que estão despreparados, seja abalado, gerando sentimentos como angústia, ansiedade e desespero, afetando diretamente o cuidador (WALDOW, 2006).

Existem os cuidadores formais, como enfermeiros e médicos. De acordo com Machado (2008), os trabalhadores de ambientes hospitalares, muitas vezes, sofrem junto ao paciente, e isso é tratado de forma natural pelos profissionais, ou ainda podem ignorar a situação, pois para tais profissionais o sofrimento faz parte da rotina do trabalho, portanto deve ser aceito sem lamento. No entanto, esses mecanismos de defesa podem afetar o profissional. "Contudo, esconder esses sentimentos não parece ser o melhor caminho para significar e compreender tais sentimentos a ponto de não se tornarem perigosos para a saúde psíquica desses profissionais" (MACHADO, 2008; p. 449).

Osório (2003) ressalta que os cuidadores também merecem cuidados para que não venham a adoecer, seja com a saúde física ou com a saúde mental. Deste modo, o apoio psicológico ao cuidador é fundamental, pois este por estar em contato direto com o paciente hospitalizado, influencia no tratamento e na busca pela cura do mesmo.

\section{O acolhimento psicológico dos cuidador familiar}

Ferreira (2001) define o acolhimento como o ato de acolher, dar amparo e hospitalidade, ou ainda conforme o Ministério da Saúde (2006), o acolhimento implica no compartilhar saberes, angústias, tomando para si a responsabilidade de acolher em suas demandas com responsabilidade e resolutividade.

De acordo com Damiani (2008), o acolhimento significa a humanização do atendimento, o que implica na garantia de acesso a todos. Diz respeito, ainda, à escuta de problemas de saúde do usuário, dando-lhe sempre uma resposta positiva e responsabilizando-se pela resolução do seu problema. Por consequência, o acolhimento deve garantir a resolução do problema do usuário.

Segundo Schneider e col. (2008), o acolhimento visa à escuta, valorização das queixas e identificação das necessidades do paciente e do familiar, é algo embasado no diálogo em que as pessoas se envolvem, estabelecendo uma relação. Ao acolher permite-se o relacionamento humanizado entre profissionais de saúde e a família/paciente. "É relevante estabelecer vínculos de confiança entre trabalhadores da saúde e a paciente/família. Quando não ocorre a cumplicidade entre ambos, pode dificultar a terapêutica proposta" (SCHNEIDER et al., 2008; p. 83). 


\section{Doença na família: uma discussão sobre o familiar cuidador}

A equipe profissional deve estar preparada para estabelecer uma relação humanizada com o paciente e a família deste. $\mathrm{O}$ acolhimento é um processo contínuo do atendimento em saúde, pois é no momento da hospitalização de um familiar que muitos indivíduos tornam-se fragilizados e temerosos, visto que existe o sofrimento e a angústia da insegurança que a doença gera, assim, paciente e familiar necessitarão da atenção dos profissionais da saúde que são vistos como possuidores de respostas para as dúvidas que emergem $(\mathrm{SCH}-$ NEIDER et al., 2008).

De acordo com Kovács (2008), profissionais da área médica são treinados, há uma "dessensibilização" para que não sofram com a morte; então as pessoas são transformadas em órgãos, o paciente vira apenas um número ou um órgão doente. É necessário que os profissionais da saúde estejam preparados para lidar não apenas com conhecimentos técnicos e científicos, mas também com sensibilidade suficiente para lidar com situações de sobrecarga emocional dos pacientes e dos familiares, o que requer habilidade para manter um cuidado humanizado pelo outro (SCHNEIDER et al., 2008).

Diante desses termos, pode-se entender que o ato de acolher é o ato humanizado que os profissionais do ambiente hospitalar devem manter com os pacientes, cuidadores e familiares. Conforme Schneider e colaboradores (2008) o acolhimento deve ser feito desde a chegada do paciente, de forma que o profissional esteja atento aos seus problemas e queixas, permitindo que o familiar se sinta acolhido, expressando seus medos e angústias. $\mathrm{O}$ familiar busca essa assistência acolhedora, pois seu estado físico e emocional está abalado, e o profissional the acolhe e cuida da sua fragilidade, criando desta maneira um vínculo, uma ligação afetiva e tornando-se uma convivência de ajuda e respeito recíproco.

Kovács (2008) afirma que quando há interação entre pacientes e familiares com a equipe profissional, os pacientes sentem-se mais acolhidos, um pouco menos frustrados e mais conformados e com a sensação de terem sido acolhidos e atendidos. Por mais que existam muitos pacientes, é importante a interação profissional-paciente ou familiar cuidador, pois o olho no olho possibilita o envolvimento profissional com o paciente; assim o paciente se sente acolhido e o profissional se aperfeiçoa por ter um contato mais humano.

O Ministério da Saúde (2006) indica que há necessidade de preparação de projetos terapêuticos individuais e coletivos com equipes de referência em atenção diária para que estendam a esses cuidadores uma postura acolhedora, que implica no compartilhamento de saberes e angústias. $\mathrm{O}$ ato da escuta e a produção de vínculo como ação terapêutica demonstra ao cuidador que ele não é apenas mais um, e sim que ele é importante e que deve ser ouvido. Conforme Laham (2004), o psicólogo dentro de uma equipe de saúde, assume a função não só de auxiliar o cuidador, mas também, 
de informar a equipe profissional como o paciente e a família estão reagindo à doença; isso poderá contribuir no tratamento do paciente, haja vista que se o cuidador está bem, passa essa segurança para o paciente que poderá reagir melhor ao tratamento.

\section{Metodologia}

Essa pesquisa se caracteriza como pesquisa de campo, do tipo exploratória e de natureza qualitativa. Segundo Gil (1991) a pesquisa tipo exploratória têm como objetivo proporcionar maior familiaridade com o problema, com vistas a torná-lo mais explícito ou a construir hipóteses, pode-se dizer que o objetivo principal e o aprimoramento de idéias ou descoberta de intuições. Seu planejamento é bastante flexível, de modo que possibilite a consideração dos mais variados aspectos relativo ao fato estudado.

Leopardi (2001) define a pesquisa qualitativa como sendo aquela que não está focalizada em contar o número de vezes em que uma variável aparece, mas sim que qualidade ela apresenta. Através dessa pesquisa, tenta-se compreender um problema da perspectiva dos sujeitos que o vivenciam; ou seja, parte de sua vida diária, sua satisfação, desapontamentos, surpresas e outras emoções, sentimentos e desejos.

A pesquisa foi realizada em maio de 2010, tendo como local o Setor de Oncologia do Hospital São José da cidade de Criciúma/SC. A escolha desse local deve-se à grande quantidade de pessoas hospitalizadas tendo como principais cuidadores os familiares, que são os sujeitos deste trabalho. A população desse estudo foi composta por 6 pessoas, 1 do sexo masculino e 5 do sexo feminino, sendo eles acompanhantes de pacientes internados no setor. Como critério de inclusão foram indicados pelo enfermeiro responsável pelo setor os cuidadores que estiveram aptos a responder as questões da pesquisa.

A coleta de dados contou como instrumento uma entrevista semi-estruturada, que foi aplicada com os acompanhantes e cuidadores dos pacientes internados no Setor de Oncologia do Hospital São José de Criciúma/SC. As entrevistas foram gravadas, e posteriormente transcritas, com consentimento dos participantes. Esta se deu de forma individual. De acordo com Minayo (2004; p. 57) "a entrevista é o procedimento mais usual no trabalho de campo. E pode ser coletiva ou individual".

A pesquisa foi fundamentada nas normas que regulamentam a Pesquisa envolvendo seres humanos, conforme resolução 196/96 do Conselho Nacional de Saúde. O Projeto de Pesquisa para o presente Artigo foi submetido ao Comitê de Ética e Pesquisa do Hospital São José e aprovado (Projeto 146/2010). 


\section{Doença na família: uma discussão sobre o familiar cuidador}

C.A.Dias \& D. Nuernberg

\section{Apresentação e análise dos dados}

O principal objetivo desse estudo é compreender a importância do acolhimento psicológico ao acompanhante e familiar do paciente hospitalizado, a partir das narrativas que apareceram nas entrevistas. A metodologia utilizada para a análise dos dados foi a análise de conteúdo, interpretando os discursos que foram obtidos por meio de aplicação do instrumento de pesquisa.

A coleta dos dados foi efetuada em um encontro realizado nas dependências do Hospital São José, da cidade de Criciúma/SC. Os sujeitos da pesquisa foram seis acompanhantes, sendo estes familiares dos pacientes hospitalizados. A pesquisadora se apresentou aos sujeitos de forma individual, divulgando o objetivo da pesquisa, seguindo com a entrevista semi-estruturada, contendo dez questões. Utilizou-se para cada participante uma numeração a fim de identificá-los, mantendo sigilo de suas identidades.

Os participantes responderam questões referentes à idade, sexo, grau de parentesco com o paciente hospitalizado, tempo de internação desse sujeito, quais os sentimentos existentes no cuidado de um familiar doente e hospitalizado, de que forma a família está se sentindo em relação à doença e a internação, se há preparo emocional desse cuidador para lidar com o paciente. Bem como, se esse cuidador necessita de apoio para isso, quais os maiores medos em relação ao cuidado com o doente, e se os cuidadores recebem apoio emocional da instituição para lidar com a situação.

Durante a pesquisa, buscou-se compreender como esses acompanhantes sentem-se ao cuidar de um familiar hospitalizado, os sentimentos, emoções e o preparo psicológico que estes têm. Dos entrevistados, as idades variam entre 31 e 71 anos. Destes, cinco são do sexo feminino e um do sexo masculino. O grau de parentesco dos sujeitos da pesquisa é: duas filhas, três esposas e um esposo. De acordo com Waldow (2007), ao longo da história, os cuidados com os que necessitavam já eram de responsabilidade das mulheres, concluindo-se que o modo de expressar cuidado, é mais evidente entre as mulheres. Em nossa literatura é enfatizado o papel da mulher enquanto cuidadora e, por conseguinte, promotora de saúde de seus familiares. Esse papel lhe possibilitou desenvolver habilidades necessárias para cumprir o cuidado junto à pessoa doente e tornar-se parceira dos serviços de saúde (ALONSO, 2003).

Grandi (1998) acrescenta que o ato de cuidar normalmente é praticado por mulheres porque esta ocupa o primeiro lugar entre os cuidadores em potencial, por estarem ligadas historicamente à responsabilidade pelos cuidados dos membros da família. Dentre esses fatores, o que leva as mulheres a serem os cuidadores em maior potencial, é o fato de terem experiência em relação às atividades domésticas aprendidas naturalmente cuidando de outras pessoas, como crianças e adultos doentes. 
Com relação ao tempo de internação desses pacientes, varia entre três e trinta e três dias, e alguns já estão em processo de internação há um ano. Portanto quando há uma melhora, recebem alta e vão para casa, ficam por lá em média uma semana e retornam ao hospital, desgastando ainda mais a saúde física e psicológica desses cuidadores, que por muitas vezes, tornam o ambiente hospitalar como lar temporário. Assim, pode-se verificar na fala do entrevistado número 6 que relata: "Faz 33 dias que eu estou aqui direto, mas porque eu que quero. Dia e noite. Meus filhos trabalham, eu não. Então eu fico aqui. Eu deito de dia, descanso. Na medida que ele tá bonzinho eu descanso, [...]. Se ele dorme de dia eu também durmo, na medida que ele dorme eu também durmo. Então eu não fico muito cansada. Mas ultimamente eu tô morando no hospital, vou, fico no máximo uma semana em casa" (Esposa, 55 anos).

Nesse mesmo sentido o entrevistado número 2 fala: "Tenho um filho de 4 anos que fica com a minha filha enquanto eu tô aqui. Eu fico aqui e a minha sogra também, mas é bem pouco. A maioria sou eu" (Esposa, 45 anos).

Confirmando a fala dos entrevistados, Sá (2002) ressalta que esses cuidadores esquecem que têm uma família que também necessita da sua presença; esquecem que também precisam de cuidados, que pertencem a um grupo familiar e que estes podem colaborar revezando o acompanhamento e o cuidado desses pacientes. Para os cuidadores em que não há revezamento do cuidado com o paciente, percebe-se um maior cansaço, mesmo que não seja físico. O estado psicológico desses cuidadores é afetado por não estarem descansando como deveriam.

No que se refere ao sentimento de cuidar de um familiar hospitalizado, os entrevistados relataram que não se sentem bem em estar no ambiente hospitalar, o entrevistado 2 afirmou: "Ninguém quer estar aqui dentro [...]; é péssimo tá aqui. Queria ir pra casa" (Esposa, 45 anos).

O entrevistado 5 descreve: "Olha é uma dificuldade, que nos primeiros momentos que a gente soube do fato o choque foi grande. Mas em razão da precisão a gente vai se superando, se acostumando estar aqui. Mas de vez em quando a gente não consegue nem falar, sofre muito" (Esposo, 53 anos).

O entrevistado 6 também se referiu: "Aqui não é um bom ambiente né, mas a gente tem que aceitar. Na hora que a gente recebe a notícia não fica bem, mas tem que aceitar né" (Esposa, 55 anos).

Diante dessas falas pode-se compreender que para os cuidadores o fato de estar num ambiente hospitalar, longe de casa é algo desgastante. Conforme Waldow (2007), o ser humano, adquire formas e manifestações de cuidar que se sofisticam. Assim sendo, o cuidar inicia-se primeiramente como forma de sobrevivência, em seguida como uma expressão de interesse e carinho. A primeira forma mostra-se em todas as espécies de seres vivos. Já a segunda é uma particularidade dos seres humanos. 


\section{Doença na família: uma discussão sobre o familiar cuidador}

Então, segundo as falas dos entrevistados, o fato de estar no hospital não é algo acolhedor, mas por amor ao familiar se submetem ao fato de estar nesse ambiente.

De acordo com Grandi (1998), o cuidador torna-se a segunda vítima, pois o ato de cuidar gera sobrecarga física e emocional. De acordo com Sá (2002), o papel de cuidador não é algo preestabelecido e ninguém está preparado para tal, por isso, quando surge à necessidade de cuidar, cada qual reage de uma maneira, de acordo com suas características particulares. O cuidador assume um papel que foi imposto pela ocasião. Durante as entrevistas, observou-se uma sensibilidade intensa em todos os entrevistados. Alguns, por razão de religiosidade mostravam-se um pouco mais seguros com relação à doença; no entanto, todos, sem nenhuma exceção, durante a entrevista se emocionaram, demonstrando fragilidade perante a situação.

Com relação à família do paciente hospitalizado, os entrevistados na sua grande maioria mencionaram o apoio e o papel fundamental que esta exerce no processo de cuidar. Afirmam ainda que todo o núcleo familiar é afetado. Verifica-se isso através das colocações do entrevistado 3: "Eles me dão muito apoio, dizem que quando ele faltar, sozinha eu não vou ficar. [...] A minha família tá tudo aborrecido. Tão tudo querendo que ele melhore pra ir embora. [...] A gente reveza bem, pra cuidar dele, vem neto, vem neta, vem filho, vem filha, vem genro. A família ajuda bastante graças a Deus" (Esposa, 71 anos).

Ainda percebem-se tais afirmações na fala do entrevistado 4: "Olha, eu moro em Mato Grosso do Sul, então vim pra ajudar os meus irmãos a cuidarem do meu pai. Porque ele tem que ter sempre alguém, então se fica sempre um só, a gente não aguenta, então tem que tá se revezando, senão ninguém güenta" (Filha, 38 anos).

Assim sendo, comprova-se a afirmação de Kübler-Ross (2000) de que os familiares desempenham papel preponderante durante o adoecimento de um membro do grupo, e suas reações muito contribuem para a própria reação do paciente. Ressalta ainda a necessidade que os membros da família têm em dosar suas energias para que não se esgotem suas forças e as tenham quando for necessário. Essa atitude evidencia-se pelo fato de os cuidadores revezarem-se para o cuidado com o paciente.

Conforme Waldow (2007), a hospitalização é um evento que gera temor nas pessoas, pois a doença é vista como ameaçadora e o estar doente é algo que se caracteriza por uma ruptura na relação do indivíduo com o mundo, pois as capacidades que eram possíveis agora já não são mais. Pode-se evidenciar essa afirmação com a fala do entrevistado 5, que relata as alterações de rotina no ambiente familiar: "[...] sai do meu serviço pra cuidar dela, só pra me dedicar [...]. Minha casa mudou da noite pro dia né, antes era ela agora eu tenho que atender ela. Eu chegava do serviço, a mesinha tava pronta, 
agora eu tenho que fazer a comida, bolo, sou eu que faço. E ainda tenho que cuidar dela né. Até quinta feira passada eu ficava sozinho aqui, mas semana passada ela deu uma crise, então a médica pediu pra se revezar um pouquinho, um conversava com o outro pra poder se superar. Eu e a cumadre fazemo o cuidado durante o dia" (Esposo, 53 anos).

Assim sendo, para Carter e Mcgoldrick (2001), quando um familiar adoece, o sistema é afetado, no geral, a doença aproxima os membros de uma família, acionando nesta o processo de socialização com a enfermidade. É nessa fase do ciclo de vida da família que os indivíduos têm maiores responsabilidades.

Concernente à sétima questão, os entrevistados demonstraram que nem todos os familiares estão preparados para lidar com o cuidado de um familiar doente. De acordo com Sa (2002), o papel de cuidador não é algo preestabelecido e ninguém está preparado para tal, por isso, cada sujeito reage de uma maneira ao se deparar com tal situação. Grandi (1998) fala que o cuidar não é algo inato, e sim algo imposto pela ocasião. Assim, o cuidador poderá vivenciar essa experiência de forma dolorosa. Quando questionado sobre o preparo emocional o entrevistado 5 afirma: "[...] não tenho não. Na hora do choque é brabo. Eu passei um choque quando a médica e a psicóloga me deram explicação, eu me senti... Eu to me esforçando pra controlar o equilíbrio, a união da família, dos filhos. Mas eu sempre choro. Eu converso com eles tudo, mas numa certa hora eu sempre choro" (Esposo, 53 anos).

Conforme Waldow (2006), o familiar normalmente não está preparado para lidar com a situação, contudo é a pessoa mais próxima do paciente, e se torna à pessoa mais apta para cuidar. Embora seja a pessoa mais indicada a estar com o paciente, este também sofre, pois se depara com situações que fazem com que seu estado psicológico e emocional que estão despreparados seja abalado, gerando sentimentos como angústia, ansiedade e desespero. O entrevistado 4 relata: "A primeira vez que ele adoeceu a gente, eu e a mãe, a gente se revezava. Eu dizia, mãe, vamo arrumar outra pessoa porque eu não tenho condição. Não dormia a noite, ficava muito debilitada. Mas agora a gente tenta ser forte, não sei, acho que Deus dá graça e a gente consegue. A gente sofre, chora, mas não adianta se descabelar, não vai adiantar nada" (Filha, 38 anos).

Embora haja sofrimento com a internação de um familiar, alguns indivíduos se apegam na fé para o enfrentamento da dor, de acordo com Feifel (1959 apud KOVÁCS, 2002), para as pessoas que mantêm algum tipo de religiosidade o enfrentamento da doença se dá de forma mais suave. O entrevistado 6 narra: "A gente que é da igreja tá sempre em oração, rezando. E isso dá bastante força. Os meus filhos são também, eles participam" (Esposa, 55 anos). 


\section{Doença na família: uma discussão sobre o familiar cuidador}

O entrevistado 4 afirma: "[...] a gente tá triste com isso, mas a gente tem que ter força, se apega a Deus, na fé. Ele também dá força pra gente" (Filha, 38 anos).

Percebe-se que para os cuidadores que têm algum tipo de religiosidade, essa se torna uma válvula de escape, pois mencionam a fé como sendo algo confortador e que lhes dá força. Durante a entrevista, quando citavam a fé e a religiosidade, esses cuidadores demonstravam uma serenidade, embora existisse a dor do sofrimento, nesse instante mostravam-se confortados.

Quando questionados se necessitam de apoio para lidar com os cuidados do familiar num ambiente hospitalar, os entrevistados relataram que sim e descrevem como principal aliado à família. De acordo com Osório (2003), os cuidadores merecem o devido apoio, tanto físico como emocional, para que não venham a adoecer. Assim, o cuidado psicológico dedicado a estes cuidadores é essencial, pois além de cuidar da própria saúde, o cuidador está em contato direto com o paciente e poderá influenciar no tratamento. $\mathrm{O}$ entrevistado 1 menciona: "Foi muito interessante num dia em que deram muita morfina pra ele e ele ficou muito fora [...]. E ai eu comecei a chorar. Sai fora do quarto e veio uma enfermeira e conversou comigo e disse, é assim mesmo ele nem sabe que está fazendo isso. [...] se não tivesse alguém que viesse conversar comigo talvez eu ia precisar de alguém em casa, e o meu dia teria ficado insuportável" (Filha, 31 anos).

Neste sentido, quando questionado o entrevistado 5 fala: "Claro. Tanto eu como a família. Nós somos muito unidos. E isso que dá força” (Esposo, 53 anos).

Conforme Grandi (1998), o cuidador é o responsável direto pelo paciente, é ele que zela tanto o estado físico como o psicológico e social, tornando-se então, cada vez mais dependente do que o cuida. Assim, o cuidador torna-se a segunda vítima, pois o ato de cuidar gera sobrecarga física e emocional.

O principal medo dos acompanhantes com relação à doença e a hospitalização do familiar é o de vivenciar um momento de dor. Segundo Sá (2002), o cuidador sofre com a descoberta da doença, e sofre ao ver seu familiar sofrendo. Tais fatos geram na família grande fragilidade diante do medo de enfrentar a doença. O entrevistado 1 relata: "O meu medo é que ele sofra, o meu medo é que ele comece a sentir muita dor e a gente não consiga controlar isso. Eu não quero que ele sofra. O meu medo é de ver ele chorando, sofrendo" (Filha, 31 anos).

O entrevistado 4 afirma: "A gente tem medo de ele vim a sentir muita dor. [...] a gente não sabe o que pode vim acontecer. A gente tem medo de ele vim a sofrer muito" (Filha, 38 anos).

Evidenciou-se a questão do medo de presenciar o sofrimento do outro. Esse sentimento gera sensação de impotência frente à situação, pois para o familiar que acompanha, não há o que fazer frente ao momento de dor. 
O momento é de total fragilidade para os familiares que cuidam do paciente, $\mathrm{o}$ fato de cuidar de alguém que amam e de ver o momento de dor deste, gera para o cuidador uma angústia muito grande, pois não há nada que se possa fazer para evitar.

É importante destacar que para esses acompanhantes a equipe profissional que compõe o ambiente hospitalar é vista como possuidores das respostas. As enfermeiras, principalmente, desempenham papel de auxiliadoras nesse processo de cuidar. Por mais que os acompanhantes mantenham constante contato com a família, dentro do hospital são as enfermeiras e enfermeiros que desempenham muitas vezes, o papel de apoio. O entrevistado 1 faz essa afirmação: "[...] num dia em que deram muita morfina pra ele e ele ficou muito fora, e ai eu dizia pai olha pra mim e ele brigava comigo, dizia ai para guria, para, vai embora! E ai eu comecei a chorar. Sai fora do quarto e veio uma enfermeira e conversou comigo e disse, é assim mesmo ele nem sabe que está fazendo isso. Então nessa hora eu precisei de alguém" (Filha, 31 anos).

É fundamental que a equipe de saúde identifique quem é o cuidador, aproximando-se deste, dando-lhe apoio e estabelecendo uma relação de confiança. O cuidador deve ser uma preocupação constante para a equipe de saúde, necessitando ser fortalecido e instigado a olhar para si próprio e assim poder cuidar do familiar doente. (MOTTA, 2004).

Desta forma, segundo Schneider e colaboradores (2008), o acolhimento dentro do ambiente hospitalar é necessário e a equipe profissional deve estar preparada para tanto. $\mathrm{O}$ acolhimento visa à escuta, valorização das queixas e identificação das necessidades do paciente e do familiar. Compreende-se assim, o sentido dessa pesquisa, que demonstrou através das entrevistas as hipóteses levantadas no projeto, afirmando a necessidade de um tratamento adequado aos familiares acompanhantes de pacientes hospitalizados.

Os familiares cuidadores deverão aprender novas habilidades para cuidar desses pacientes, além de que necessitam não apenas de conhecimentos técnicos, mas também de apoio do ponto de vista psicológico para poder superar situações delicadas tais como: cuidar do familiar que agora está limitado ao leito hospitalar. $\mathrm{O}$ fato de esses pacientes tornarem-se dependentes totais desse cuidador, entre outras situações gera sobrecarga emocional nos cuidadores que necessitam da devida atenção para que se sintam psicologicamente fortes e lidem com a situação da forma mais natural possível.

\section{Considerações finais}

A internação de um familiar doente gera uma crise no grupo familiar e do cuidador, que geralmente será alguém da família que tem forte ligação afetiva com o doente. Através do instrumento de pesquisa utilizado, 


\section{Doença na família: uma discussão sobre o familiar cuidador}

foi possível fazer uma análise das mudanças ocorridas na vida dos familiares cuidadores de pacientes hospitalizados. Constatou-se que quando uma doença atinge um membro da família, todo o grupo familiar é afetado, desde a criança, que sente a ausência da mãe no lar, até o esposo, que no papel de cuidador assume as tarefas que antes eram da esposa. De uma forma geral, esses cuidadores adoecem psicologicamente, pois além de receberem a notícia de que um familiar, uma pessoa que amam passará por um momento de doença, recebem ainda o impacto de cuidar desse paciente.

Embora os familiares cuidadores demonstrassem nas entrevistas que se sentem bem em estar ao lado de quem amam num momento difícil, evidenciam a fragilidade que passam juntamente com todo o grupo familiar, que também é afetado. De uma forma geral, esses familiares sofrem as mudanças no cotidiano e as mudanças físicas, como dormir mal, o estresse e a ansiedade. O medo de ver o familiar sofrendo por si só, já gera toda essa mudança na vida e na saúde desses acompanhantes.

Com esse estudo, foi possível responder o problema da pesquisa que buscava compreender qual a importância do acolhimento psicológico ao acompanhante familiar do paciente hospitalizado.

Durante o processo, compreendeu-se a necessidade de assistência psicológica aos acompanhantes, embora na sua maioria tenham o apoio da família, dentro do ambiente hospitalar sentem-se angustiados ao se depararem com situações que não fazem parte do cotidiano familiar. O simples fato de receberem informações do estado de saúde do paciente, já conforta esses familiares, que muitas vezes, sem saber do real diagnóstico, ficam na angústia da dúvida. O esclarecimento das dúvidas e o conhecimento da real condição do familiar amenizam o sofrimento desses cuidadores.

Durante a internação, os cuidadores encontram formas de acolhimento dentro do hospital que aliviam a ansiedade da espera, como criar vínculos de amizades com os outros acompanhantes que estão no hospital. O simples fato de ter alguém para poder compartilhar os sentimentos e as experiências já vividas, alivia o sofrimento dos cuidadores, pois percebem que não estão sozinhos e que não são os únicos a sofrerem. De acordo com as respostas dos entrevistados, há necessidade de um profissional que explique com precisão o estado de saúde do familiar, que ajude esses acompanhantes a enfrentarem o momento, buscando com esses o auxílio emocional, confortando no momento em que recebem tais informações, que geralmente é algo desagradável.

Diante disso, finaliza-se constatando que os cuidadores sofrem um grande desgaste emocional e físico, e por isso precisam de um tratamento mais humanizado por parte das instituições e profissionais de saúde, que nos dados da pesquisa se mostra deficiente e muitas vezes, inexistente. 
Portanto, é preciso um novo olhar destes profissionais para a ajuda e o suporte emocional dos cuidadores, haja vista que estes são o principal apoio que os profissionais da saúde e os próprios doentes recebem.

\section{Referências bibliográficas}

ALONSO, I.L.K. Luzes e sombra no ritual do encontro entre o universo profissional e o mundo da intimidade familiar: a intervenção profissional na saúde da família em âmbito domiciliar. Tese de Doutoramento em Filosofia da Enfermagem. Florianópolis: Programa de Pós-Graduação em Enfermagem, Universidade Federal de Santa Catarina, 2003.

BOFF, L. Saber cuidar: ética do humano - compaixão pela terra. $14^{a}$ Edição. Petrópolis, Vozes, 2008.

BRASIL. Secretaria de Atenção à Saúde. Núcleo Técnico da Política Nacional de Humanização. Acolhimento nas práticas de produção de saúde. $2^{\mathrm{a}}$ Edição. Brasília: Ministério da Saúde, 2006.

CARTER, B. \& MCGOLDRICK, M. As mudanças no ciclo de vida familiar: uma estrutura para a terapia familiar. $2^{\text {a }}$ Edição. Porto Alegre: Artmed, 2001.

CELICH, K.L.S. \& BATISTELLA, M. ser cuidador familiar do portador de doença de Alzheimer: vivências e sentimentos desvelados. Cogitare Enferm.,12(2):143-149, 2007.

DAMIANI, F.F. Acolhimento: um caminho para humanização em saúde pública em um município da região carbonífera. Monografia de Especialização em Saúde Coletiva. Criciúma: Universidade do Extremo Sul Catarinense, 2008.

FERREIRA, A.B.H. Dicionário da língua portuguesa. $3^{\text {a }}$ Edição. Rio de Janeiro: Nova Fronteira, 1999.

GIL, A.C. Como elaborar projetos de pesquisa. $4^{\text {a }}$ Edição: São Paulo: Atlas, 2002.

GRANDI, I. Conversando com o cuidador a doença de Alzheimer. Belém: Grafisa, 1998.

KOVÁCS, M.J. Morte e existência humana: caminhos de cuidados e possibilidades de intervenção. Rio de Janeiro: Guanabara Koogan, 2008.

KÜBLER-ROSS, E. Sobre a morte e o morrer. $8^{\text {a }}$ Edição. São Paulo: Martins Fontes, 2000. 


\section{Doença na família: uma discussão sobre o familiar cuidador}

LAHAN, C.F. Peculiaridades do Atendimento Psicológico em Domicílio e o Trabalho em Equipe. Psicol. Hosp. 2(2), 2004.

LEOPARDI, M. Metodologia da pesquisa na saúde. Santa Maria/RS, 2001.

MACHADO, A.G. \& MERLO, A.R.C. Cuidadores: seus amores e suas dores. Psicologia e Sociedade, 2(3), 2008.

MINAYO, M.C.S. Pesquisa social: teoria, método e criatividade. $23^{\text {a }}$ Edição. Petrópolis: Vozes, 2004.

MINUCHIN, S. Famílias: funcionamento \& tratamento. Porto Alegre: Artmed 1990.

MOTTA, M.G.C. da. O entrelaçar de mundos: família e hospital. In: I. ELSEN; S.S. MARCON \& SILVA, M.R.S. O viver em família e sua interface com a saúde e a doença. Pp. 157-80. Maringá: Eduem, 2004.

OSÓRIO, L.C. Família hoje. Porto Alegre: Artes Médicas Sul, 1996.

OSÓRIO, L.C. Psicologia grupal: uma nova disciplina para o advento de uma era. Porto Alegre: ARTMED, 2003.

PRADO, D. \& DAMIANI, E. O que é família. $8^{\text {a }}$ Edição. São Paulo: Editora Brasiliense, 1986.

RELVAS, A.P. Ciclo vital da família: perspectiva sistêmica. $2^{\text {a }}$ Edição. Porto: Edições Afrontamento, 2000.

ROMANO, B.W. Princípios para a prática da psicologia clínica em hospitais. São Paulo: Casa do Psicólogo, 1999.

SA, M.C.N. Um estudo sobre os cuidadores familiares de pacientes internados com doenças hematológicas. Psicologia, 3(1): 124-41, 2002.

SCHNEIDER, D.G. et al. Acolhimento ao paciente e família na unidade coronariana. Texto Contexto - Enferm., 17(1): 81-9, 2008.

WALDOW, V.R. Cuidar: expressão humanizadora da enfermagem. $2^{\text {a }}$ Edição. Petrópolis: Vozes, 2007. 